\title{
How to find and diagnose a CDG due to defective N-glycosylation
}

\author{
Dirk J. Lefeber • Eva Morava $\cdot$ Jaak Jaeken
}

Received: 1 June 2011 /Revised: 10 June 2011 / Accepted: 16 June 2011 /Published online: 8 July 2011

(C) The Author(s) 2011. This article is published with open access at Springerlink.com

The group of Congenital Disorders of Glycosylation (CDG) is expanding rapidly since the first clinical description of the N-glycosylation defect PMM2-CDG (CDG-Ia) in 1980 (Jaeken et al. 1980). Since then, more than 50 defects have been identified in protein $\mathrm{N}$-glycosylation (some of them also associated with an O-glycosylation defect), in protein O-glycosylation only and in lipid glycosylation (GPI anchor and glycosphingolipid synthesis). Here, we provide a simple approach to the clinical, biochemical and genetic diagnosis of CDG due to a $\mathrm{N}$-glycosylation defect (including combined $\mathrm{N}$ - and O-glycosylation defects).

\section{When to consider a CDG due to a N-glycosylation defect}

Most CDG with a N-glycosylation defect are multi-organ diseases with neurological involvement. Only few of

Communicated by: Verena Peters

Competing interest: None declared.

\section{J. Lefeber}

Department of Neurology, Laboratory for Genetic,

Endocrine and Metabolic Disease,

Nijmegen, The Netherlands

D. J. Lefeber $(\bowtie) \cdot$ E. Morava

Institute for Genetic and Metabolic Disease,

Nijmegen, The Netherlands

e-mail: D.Lefeber@neuro.umcn.nl

E. Morava

Department of Pediatrics,

Radboud University Nijmegen Medical Centre,

Nijmegen, The Netherlands

J. Jaeken

Universitair Ziekenhuis Gasthuisberg,

Leuven, Belgium these CDG are known as non-neurological disorders, such as MPI-CDG (de Lonlay and Seta 2009), DPM3CDG (Lefeber et al. 2009) and SEC23B-CDG (Schwarz et al. 2009). Nearly all organs have been reported to be affected in CDG (Jaeken 2010). One should thus screen for CDG (i) in any unexplained neurological syndrome, particularly when associated with other organ disease, (ii) and also in any unexplained syndrome even without neurological involvement.

Experience gained in the last decade has shown that a number of clinical clues might alert for a CDG and that some of these clues might also provide a hint for a specific CDG subtype, either in the CDG-I group (Morava et al. 2008) or in the CDG-II group (Mohamed et al. 2011). These specific features include also the well known abnormality in fat distribution or cutis laxa. A brief overview of alerting clinical features is presented in Table 1 and currently known CDG subtypes are tabulated in Table 2 . A laboratory finding to be added to this list is syndromic factor XI deficiency in CDG-I, and in an unknown number of CDG-II defects.

\section{How to screen for CDG due to a N-glycosylation defect}

Since its introduction in 1984, isoelectric focusing (IEF) of serum transferrin is still the method of choice for the diagnosis of $\mathrm{N}$-glycosylation disorders associated with sialic acid deficiency (Jaeken et al. 1984). More recently, HPLC (Helander et al. 2001) and capillary zone electrophoresis (Carchon et al. 2004) have been introduced as well as mass spectrometry (Babovic-Vuksanovic and O'Brien 2007). In the absence of a protein polymorphism, the isoelectric point of transferrin is determined only by its glycosylation status. A protein polymorphism can be identified by incubation of the sample with commercial 
Table 1 Overview of suggestive clinical features

\begin{tabular}{|c|c|c|}
\hline Clinical features suggestive for a distinct CDG type & Suspected gene defect & Suggested analysis after transferrin screening \\
\hline Syndromic fat pads and/or inverted nipples & PMM2 & PMM enzyme measurement \\
\hline \multirow[t]{3}{*}{ Chronic diarrhea } & MPI & MPI enzyme measurement \\
\hline & ALG6 & LLO analysis in fibroblasts \\
\hline & ALG8 & “ \\
\hline Liver fibrosis & MPI & MPI enzyme measurement \\
\hline \multirow[t]{3}{*}{ Ichthyosis syndrome } & MPDU1 & LLO analysis in fibroblasts \\
\hline & DOLK & Mutation analysis \\
\hline & SRD5A3 & Plasma polyprenols \\
\hline \multirow[t]{2}{*}{ Neurosyndromatic cataract and/or coloboma } & SRD5A3 & Plasma polyprenols \\
\hline & ALG2 & Mutation analysis \\
\hline \multirow[t]{2}{*}{ Neurosyndromatic sensorineural deafness } & ALG11 & LLO analysis in fibroblasts \\
\hline & RFT1 & Mutation analysis \\
\hline Neurosyndromatic radio-ulnar synostosis & MGAT2 & Serum glycan profiling \\
\hline \multirow{2}{*}{$\begin{array}{l}\text { Neurosyndromatic recurrent infections with unusually } \\
\text { high leukocytosis }\end{array}$} & SLC35C1 & Bombay blood group \\
\hline & & Serum glycan profiling \\
\hline \multirow[t]{2}{*}{ Neurological syndrome with Bombay bloodgroup } & SLC35C1 & Serum glycan profiling \\
\hline & & Mutation analysis \\
\hline \multirow[t]{2}{*}{ Cerebrocostomandibular syndrome } & COG1 & Serum ApoC3 IEF \\
\hline & & Mutation analysis \\
\hline \multirow[t]{2}{*}{ Neurological syndromes with episodic hyperthermia } & COG7 & Serum ApoC3 IEF \\
\hline & & Mutation analysis \\
\hline \multirow[t]{2}{*}{ Cutis laxa syndrome } & ATP6V0A2 & Serum ApoC3 IEF \\
\hline & & Mutation analysis \\
\hline Congenital dyserythropoietic anemia type II or HEMPAS & SEC23B & Mutation analysis \\
\hline \multirow[t]{5}{*}{ Syndromic cardiomyopathy } & PMM2 & PMM enzyme measurement \\
\hline & ALG1 & LLO analysis in fibroblasts \\
\hline & DOLK & Mutation analysis \\
\hline & DPM1 & \\
\hline & DPM3 & \\
\hline
\end{tabular}

sialidase, by analysis of different proteins such as thyroxine-binding globulin (TBG) or by analysis of parental serum samples. In human plasma, the tetrasialotransferrin fraction is the most abundant form. Children younger than 1 month can show mildly elevated underglycosylated transferrin isoforms as compared to older children. Also, the diagnosis of CDG might be missed in very young children, in whom the profile becomes abnormal after 1-2 months of age. A few CDG patients have been described with a normal profile particularly in adolescent and adult age (Vermeer et al. 2007). Before proceeding with further diagnostics, it is important to rule out secondary causes of abnormal transferrin profiles, such as fructosemia, galactosemia, alcohol abuse and bacterial sialidase.

In general, two diagnostic types of abnormal profiles can be distinguished (Fig. 1a): (i) a type 1 pattern in CDG-I, characterized by an increase of di- and/or asialotransferrin; (ii) a type 2 pattern in CDG-II, characterized by an increase of tri-, di-, mono-and/or asialotransferrin.

The type 1 pattern (CDG-I) points to an assembly or transfer defect of the dolichol-linked glycan (in the cytosol or ER glycosylation pathway). Measurement of phosphomannomutase activity in fibroblasts or leukocytes is the next step for further diagnostics because PMM2-CDG (CDG-Ia) is by far the most frequent N-glycan assembly defect. In case of a purely hepato-intestinal clinical presentation, the activity of phosphomannose isomerase should be measured for diagnosis of MPI-CDG (CDG-Ib), which is a treatable disease. A normal activity of these enzymes necessitates analysis of the lipid-linked oligosaccharides (LLO; more specifically dolichol-linked oligosaccharides) in fibroblasts or other more specific assays to identify the known (or still unknown) CDG-I subtype. The recently identified SRD5A3-CDG could be diagnosed directly by analysis of plasma polyprenols (Morava et al. 2010). 
Table 2 Overview of current CDG subtypes

\# Official gene names were used (www.genenames.org) to indicate the new nomenclature. In parenthesis (e.g. Ia for CDG-Ia) the formerly used nomenclature. $* \mathrm{MS}=$ serum N-glycan profiling

Fig. 1 Isofocusing techniques in the screening for CDG. a. Isofocusing of plasma transferrin for detection of $\mathrm{N}$ glycosylation defects. Indicated is the most abundant glycan isoform of transferrin with two bi-antennary N-glycans, corresponding with tetrasialotransferrin. Lane 1: control, lane 2: CDG-I profile, lane 3: asialo type 2 profile, lane 4 : disialo type 2 profile. b. Isofocusing of plasma apolipoprotein $\mathrm{C} 3$ for detection of mucin type O-glycosylation defects. Lane 1: control, lane 2: ApoC3-0 profile, lane 3: ApoC3-1 profile

\begin{tabular}{|c|c|c|c|c|}
\hline CDG type\# & Gene, Protein & TIEF & ApoCIII & Alternative assay \\
\hline PMM2-CDG (Ia) & $P M M 2$, Phosphomannomutase & Type I & & \\
\hline MPI-CDG (Ib) & MPI, Phosphomannose isomerase & Type I & & \\
\hline ALG6-CDG (Ic) & $A L G 6$, Glucosyltransferase I & Type I & & \\
\hline ALG3-CDG (Id) & $A L G 3$, Mannosyltransferase VI & Type I & & \\
\hline DPM1-CDG (Ie) & $D P M 1$, Dol-P-Man synthase & Type I & & \\
\hline MPDU1-CDG (If) & MPDU1, Dol-P-Man utilization protein & Type I & & \\
\hline ALG12-CDG (Ig) & $A L G 12$, Mannosyltransferase VIII & Type I & & \\
\hline ALG8-CDG (Ih) & $A L G 8$, Glucosyltransferase II & Type I & & \\
\hline ALG2-CDG (Ii) & $A L G 2$, Mannosyltransferase II & Type I & & \\
\hline DPAGT1-CDG (Ij) & $D P A G T 1$, GlcNActransferase I & Type I & & \\
\hline ALG1-CDG (Ik) & $A L G 1$, Mannosyltransferase I & Type I & & \\
\hline ALG9-CDG (IL) & $A L G 9$, Mannosyltransferase VII & Type I & & \\
\hline DOLK-CDG (Im) & $D O L K$, Dolichol kinase & Type I & & \\
\hline RFT1-CDG (In) & $R F T 1$, RFT1 protein & Type I & & \\
\hline DPM3-CDG (Io) & DPM3, Dol-P-Man synthase & Type I & & \\
\hline ALG11-CDG (Ip) & $A L G 11$, Mannosyltransferase III & Type I & & \\
\hline SRD5A3-CDG (Iq) & $S R D 5 A 3$, Steroid $5 \alpha$ reductase 3 & Type I & & \\
\hline MGAT2-CDG (IIa) & MGAT2, GlcNActransferase II & Type II & normal & MS* \\
\hline TUSC3-CDG & TUSC3, Oligosaccharyltransferase subunit & normal & normal & gene \\
\hline MAGT1-CDG & MAGT1, Oligosaccharyltransferase subunit & & & \\
\hline GCS1-CDG (IIb) & MOGS, Glucosidase I (GCS1) & normal & normal & Urine oligosaccharides \\
\hline SLC35C1-CDG (IIc) & SLC35Cl, GDP-fucose transporter & normal & normal & Bombay blood group, MS* \\
\hline B4GALT1-CDG (IId) & $B 4 G A L T 1$, Galactosyltransferase & Type II & normal & MS* \\
\hline SLC35A1-CDG (IIf) & SLC35A1, CMP-NeuAc transporter & normal & normal & CD15s on leukocytes \\
\hline- & COG1-8, COG $1-8$ subunits & Type II & abnormal & \\
\hline- & $\begin{array}{l}\text { ATP } 6 \text { VOA2, vesicular } \mathrm{H}^{(+)} \text {-ATPase } \\
\text { subunit a2 }\end{array}$ & Type II & abnormal & \\
\hline
\end{tabular}
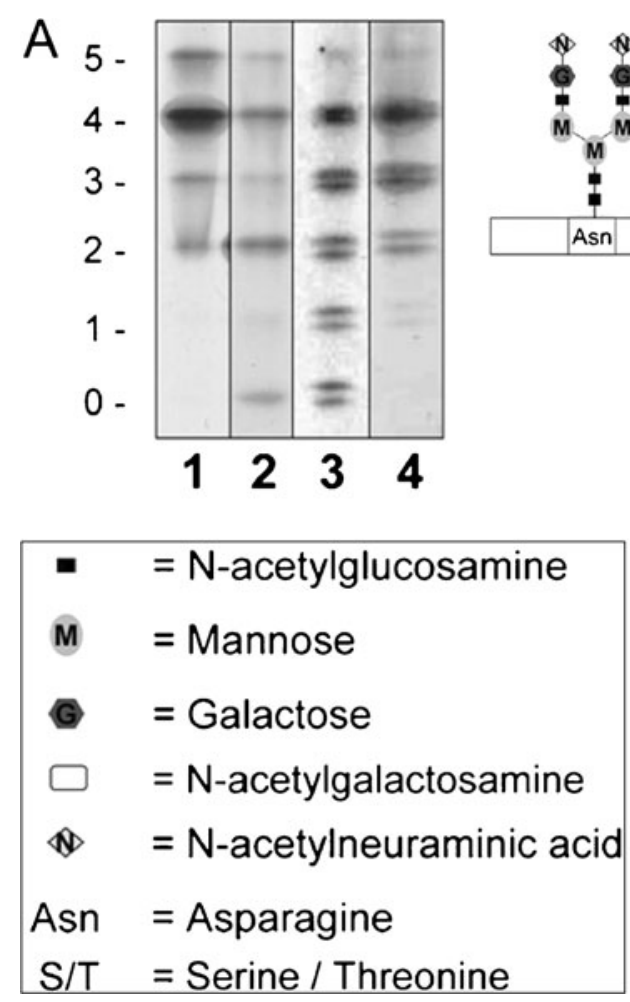

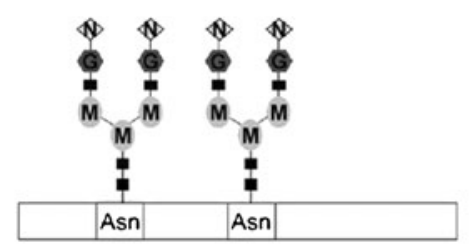

B

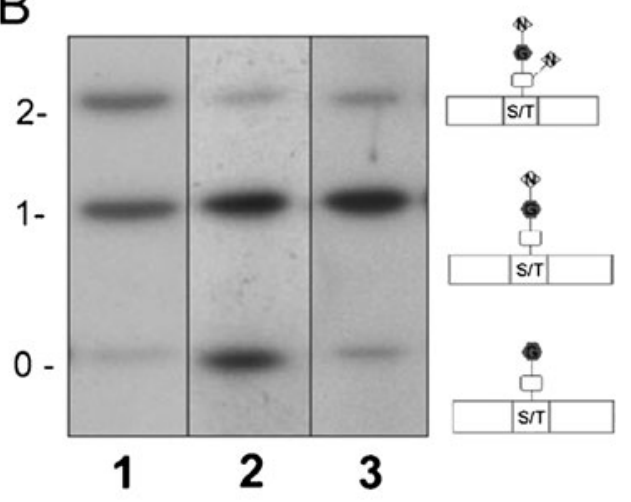


The type 2 pattern (CDG-II) indicates a processing defect after glycan transfer in the ER or during Golgi glycosylation. Not all processing defects can be picked up by transferrin IEF. Patients with GCS1, SLC35C1 (fucose has no electric charge) and SLC35A1 defects (formerly CDG-IIb, -IIc and CDG-IIf) have been described with a normal transferrin IEF profile. Type 2 patterns can show an asialo type 2 profile with increased asialo- to trisialotransferrin, or a disialo type 2 profile with increased disialo- and trisialotransferrin. The next step in the identification of the CDG-II subtypes is mass spectrometry of isolated serum N-glycans (Guillard et al. 2011). This will permit to identify isolated N-glycosylation defects as MGAT2-CDG (CDG-IIa) or B4GALT1-CDG (CDG-IId) and secondary causes, but most CDG-II types are associated with an aspecific glycan profile. In the latter situation, the possibility of an associated mucin type Oglycosylation defect should be investigated by isoelectrofocusing of serum apolipoprotein C-III (APOC3). This protein contains a single core 1 mucin type O-glycan on Thr-74. Abnormal profiles (Fig. 1b) include an increased monosialo APOC3 with decreased disialo APOC3 (a so-called APOC3-1 profile) or an increased asialo APOC3 (a so-called APOC3-0 profile) (Wopereis et al. 2005). Young children in the first months of life can present with an APOC3-2 profile in which an increase of disialo APOC 3 is observed. In our experience, the latter pattern can also be observed in patients with severe liver pathology.

Currently, no genetic glycosylation disorders have been described with an isolated abnormality of the APOC3 profile. However, several defects are known with a combined N- and O-glycosylation defect. In general, these defects are characterized by abnormal functioning of the secretory pathway, such as abnormal retrograde trafficking or abnormal acidification. If the patient presents with clinical symptoms of cutis laxa, mutation analysis of the ATP6V0A2 gene is indicated. It should be noted that ATP6V0A2-CDG patients younger than 6 months of age can present with normal transferrin glycosylation, while apolipoprotein C-III isofocusing is abnormal. In all other cases, we recommend to look for a defect in one of the COG (conserved oligomeric Golgi complex) subunits by mutation analysis of the COG1-8 subunit genes.

The emerging innovative next-generation sequencing techniques like whole-exome-sequencing will provide new opportunities to unravel genetic causes for glycosylation disorders, such as the CDG-II trafficking defects, but also the many glycosylation defects that cannot be identified via transferrin screening.

Open Access This article is distributed under the terms of the Creative Commons Attribution Noncommercial License which permits any noncommercial use, distribution, and reproduction in any medium, provided the original author(s) and source are credited.

\section{References}

Babovic-Vuksanovic D, O'Brien JF (2007) Laboratory diagnosis of congenital disorders of glycosylation type I by analysis of transferrin glycoforms. Mol Diagn Ther 11:303-311

Carchon HA, Chevigné R, Falmagne JB, Jaeken J (2004) Diagnosis of congenital disorders of glycosylation by capillary zone electrophoresis of serum transferrin. Clin Chem 50:101111

de Lonlay P, Seta N (2009) The clinical spectrum of phosphomannose isomerase deficiency, with an evaluation of mannose treatment for CDG-Ib. Biochim Biophys Acta 1792:841-843

Guillard M, Morava E, van Delft FL, Hague R, Korner C, Adamowicz M, Wevers RA, Lefeber DJ (2011) Plasma N-glycan profiling by mass spectrometry for congenital disorders of glycosylation type II. Clin Chem 57:593-602

Helander A, Eriksson G, Stibler H, Jeppsson JO (2001) Interference of transferrin isoform types with carbohydrate-deficient transferrin quantification in the identification of alcohol abuse. Clin Chem 47:1225-1233

Jaeken J (2010) Congenital disorders of glycosylation. Ann N Y Acad Sci 1214:190-198

Jaeken J, Vanderschueren-Lodewyckx M, Casaer P et al. (1980) Familial psychomotor retardation with markedly fluctuating serum prolactin, FSH and GH levels, partial TBG deficiency, increased serum arylsulphatase A and increased CSF protein: a new syndrome? Pediatr Res 14:179

Jaeken J, van Eijk HG, van der Heul L, Corbeel L, Eeckels R, Eggermont E (1984) Sialic acid-deficient serum and cerebrospinal fluid transferrin in a newly recognized genetic syndrome. Clin Chim Acta 144:245-247

Lefeber DJ, Schonberger J, Morava E, Guillard M, Huyben KM, Verrijp K, Grafakou O, Evangeliou A, Preijers FW, Manta P et al. (2009) Deficiency of Dol-P-Man synthase subunit DPM3 bridges the congenital disorders of glycosylation with the dystroglycanopathies. Am J Hum Genet 85:76-86

Mohamed M, Guillard M, Wortmann SB, Cirak S, Marklova E, Michelakakis H, Korsch E, Adamowicz M, Koletzko B, van Spronsen FJ et al. (2011) Clinical and diagnostic approach in unsolved CDG patients with a type 2 transferrin pattern. Biochim Biophys Acta 1812:691-698

Morava E, Wosik H, Karteszi J, Guillard M, Adamowicz M, SykutCegielska J, Hadzsiev K, Wevers RA, Lefeber DJ (2008) Congenital disorder of glycosylation type Ix: review of clinical spectrum and diagnostic steps. J Inherit Metab Dis $31: 450-456$

Morava E, Wevers RA, Cantagrel V, Hoefsloot LH, Al-Gazali L, Schoots J, van Rooij A, Huijben K, van Ravenswaaij-Arts CM, Jongmans MC et al. (2010) A novel cerebello-ocular syndrome with abnormal glycosylation due to abnormalities in dolichol metabolism. Brain 133:3210-20

Schwarz K, Iolascon A, Verissimo F, Trede NS, Horsley W, Chen W, Paw BH, Hopfner KP, Holzmann K, Russo R et al. (2009) Mutations affecting the secretory COPII coat component SEC23B cause congenital dyserythropoietic anemia type II. Nat Genet 41:936-940

Vermeer S, Kremer HP, Leijten QH, Scheffer H, Matthijs G, Wevers RA, Knoers NA, Morava E, Lefeber DJ (2007) Cerebellar ataxia and congenital disorder of glycosylation Ia (CDG-Ia) with normal routine CDG screening. J Neurol 254:1356-1358

Wopereis S, Morava E, Grunewald S, Adamowicz M, Huijben KM, Lefeber DJ, Wevers RA (2005) Patients with unsolved congenital disorders of glycosylation type II can be subdivided in six distinct biochemical groups. Glycobiology 15:1312-1319 